7th International Symposium on Superalloy 718 and Derivatives Edited by: E.A. Ott, J.R. Groh, A. Banik, I. Dempster, T.P. Gabb, R. Helmink, X. Liu, A. Mitchell, G.P. Sjöberg, and A. Wusatowska-Sarnek TMS (The Minerals, Metals \& Materials Society), 2010

\title{
SERRATED YIELDING IN ALLOY 718
}

\section{Sachin Nalawade ${ }^{1}$, Sundararaman Mahadevan, Jung Bahadur Singh, Kishore Ramaswamy and Amit Verma}

\author{
Structural Metallurgy Section, Mechanical Metallurgy Section \\ Bhabha Atomic Research Centre, Mumbai 400085, India
}

Key Words: Nickel-based superalloys, dynamic strain aging, serrations, high temperature deformation, transmission electron microscopy, Alloy 718.

\begin{abstract}
Alloy 718 has been reported to undergo serrated yielding (SY) phenomenon over the temperature regime that coincides with its useful service temperature range. The SY is reported to reduce ductility in several alloy systems. The present paper reports the results of detailed investigation carried out on SY phenomenon in Alloy 718 in three different microstructural conditions viz. solution annealed (ST), $\gamma^{\prime \prime}$ precipitated (STA) and $\delta$ precipitated (DELTA). Based on the estimated activation energy for appearance and disappearance of serrations as well as the nature of serrations, two regimes of dynamic strain ageing (DSA) have been identified - one below $525^{\circ} \mathrm{C}$ controlled by diffusion of interstitial carbon and the other above $525^{\circ} \mathrm{C}$ controlled by diffusion of substitutional niobium atom. The initial microstructure appeared to strongly influence the temperature regime of serrated flow. The mechanism for the delayed disappearance of serrations in ST specimens has been identified from TEM examination of deformed specimens.
\end{abstract}

\section{Introduction}

DSA phenomenon has been the subject of extensive study in many commercial nickel base superalloys because of the coincidence of the temperature range over which this phenomena occurs with the useful service temperature of the alloys. Its occurrence has been attributed to interaction of mobile dislocations with diffusing interstitial as well as substitutional solute atoms [1-9]. This phenomenon has been observed in many nickel base superalloys in different microstructural conditions over a range of temperatures and strain rates [1-10]. Different approaches have been used in modeling the DSA [11,12], which are based on relating the drop in the flow stress in stress-strain curves either to the dislocations breaking away from the pinning atoms or to the new dislocations being formed. The activation energy (Q) estimated from the plots of i) the critical strain for the onset of serrations $\left(\varepsilon_{\mathrm{ca}}\right)$ against strain rate as well as temperature [1-8], ii) the critical strain for the disappearance of serrations $\left(\varepsilon_{\mathrm{cd}}\right)$ against temperature [2], iii) stress drop $(\Delta \sigma)$ against temperature $[1,2,6]$, iv) the strain rate for the presence/absence of serrations to the temperature $[3,6]$ has been employed to identify the mechanism and the solute responsible for the DSA phenomenon. 
Alloy 718 is widely used in gas turbine and related applications due to its good mechanical properties and structural stability at intermediate temperatures. Following some of the methods mentioned above, Hayes and Hayes [1,2] attributed the diffusion of interstitial carbon atoms forming atmospheres around moving dislocations to be responsible for serrated yielding in aged Inconel 718, solution annealed Inconel 600 and aged Waspalloy in the temperature range of $490^{\circ} \mathrm{C}$ to $860^{\circ} \mathrm{C}$. Chen and Chaturvedi [4], in their study on deformation behavior of aged Alloy 718 in the temperature range of $300^{\circ} \mathrm{C}$ to $575^{\circ} \mathrm{C}$, have arrived at similar conclusions that the interstitial carbon atom is responsible for serrated phenomenon irrespective of the operative dislocation precipitate interaction mechanism. Hale et al. [6], from the estimation of activation energy, have reported that the lattice diffusion of interstitial carbon atoms at lower temperatures $\left(125^{\circ} \mathrm{C}\right.$ to $\left.425^{\circ} \mathrm{C}\right)$ and the substitutional chromium atoms at higher temperatures $\left(475^{\circ} \mathrm{C}\right.$ to $625^{\circ} \mathrm{C}$ ) is responsible for serrated yielding in Inconel 718 process annealed at $1000^{\circ} \mathrm{C}$. In a recent study, Nalawade et al. [8] have attributed the serrated phenomenon in Alloy 718 to diffusion of interstitial carbon atoms below $0.5 \mathrm{~T}_{\mathrm{M}}$ and to both interstitial and substitutional solutes at higher temperatures. However, in Alloy 625, which belongs to the same class of $\gamma^{\prime \prime}$ strengthened material as Inconel 718, the serrated behavior in solution treated [13] and in long term service exposed alloy [3] in the temperature range of $250^{\circ} \mathrm{C}$ to $750^{\circ} \mathrm{C}$ was attributed to the diffusion of relatively slow moving molybdenum atoms in the lattice. From the literature survey mentioned above, it is clear that most of the studies were carried out mainly in solution treated or solution treated / aged microstructural conditions and a consensus exists for the mechanism (diffusion of the interstitial carbon atoms) responsible for serrated phenomenon at low temperatures while for higher temperatures there is divergence of opinion as to which element is responsible for the DSA.

The nominal composition (in wt. \%) of the commercial Alloy 718 used in this study was $\mathrm{Ni}-$ $18.37 \% \mathrm{Cr}-18.06 \% \mathrm{Fe}-6 \% \mathrm{Nb}-2.91 \% \mathrm{Mo}-1 \% \mathrm{Al}-0.45 \% \mathrm{Ti}-0.21 \% \mathrm{Mn}-0.29 \% \mathrm{Si}-$ $0.02 \% \mathrm{C}$. Precipitation strengthening is primarily derived from the $\gamma^{\prime \prime}$ phase (an ordered tetragonal phase with $\mathrm{D}_{22}$ structure) $[14,15]$. In addition, a metastable $\gamma^{\prime}$ phase (an ordered fcc phase with $\mathrm{L}_{2}$ structure) forms in a small volume fraction $[16,17]$ and an equilibrium $\delta$ phase (an ordered orthorhombic phase with $\mathrm{D} 0_{\mathrm{a}}$ structure) forms at higher temperatures [17]. Chemical composition of both the $\gamma^{\prime \prime}$ and the $\delta$ phases are based on the $\mathrm{Ni}_{3} \mathrm{Nb}$ composition $[14,17]$. The DSA studies were carried out in three microstructural conditions, viz., solution treated (ST), solution treated and aged (STA) and $\delta$ precipitated (DELTA) microstructures. The observations are rationalized on the basis of activation energy for diffusion of different solutes in serrated regime reported in the literature and their concentrations in the matrix of the solution treated and aged material. Detailed transmission electron microscopic examination of the fractured specimens has been carried out with a view to identify the solute element as well as the mechanism responsible for DSA at high temperatures.

\section{Experimental Procedure}

A $5.0 \mathrm{~mm}$ thick sheet of the alloy was cold rolled with intermediate annealing to a thickness of $1.5 \mathrm{~mm}$, and machined into flat samples of gage dimensions of $1.5 \times 4.0 \times 12.6 \mathrm{~mm}$. The samples were sealed in silica capsules under helium atmosphere and heat treated to produce three different microstructures, viz. i) solution treated at $1100^{\circ} \mathrm{C}$ for $1 \mathrm{~h}$ and water quenched (ST), ii) $\mathrm{ST}$ alloy aged at $700^{\circ} \mathrm{C}$ for $50 \mathrm{~h}$ to precipitate $\gamma^{\prime}$ and $\gamma^{\prime \prime}$ precipitates (STA) and iii) ST alloy aged 

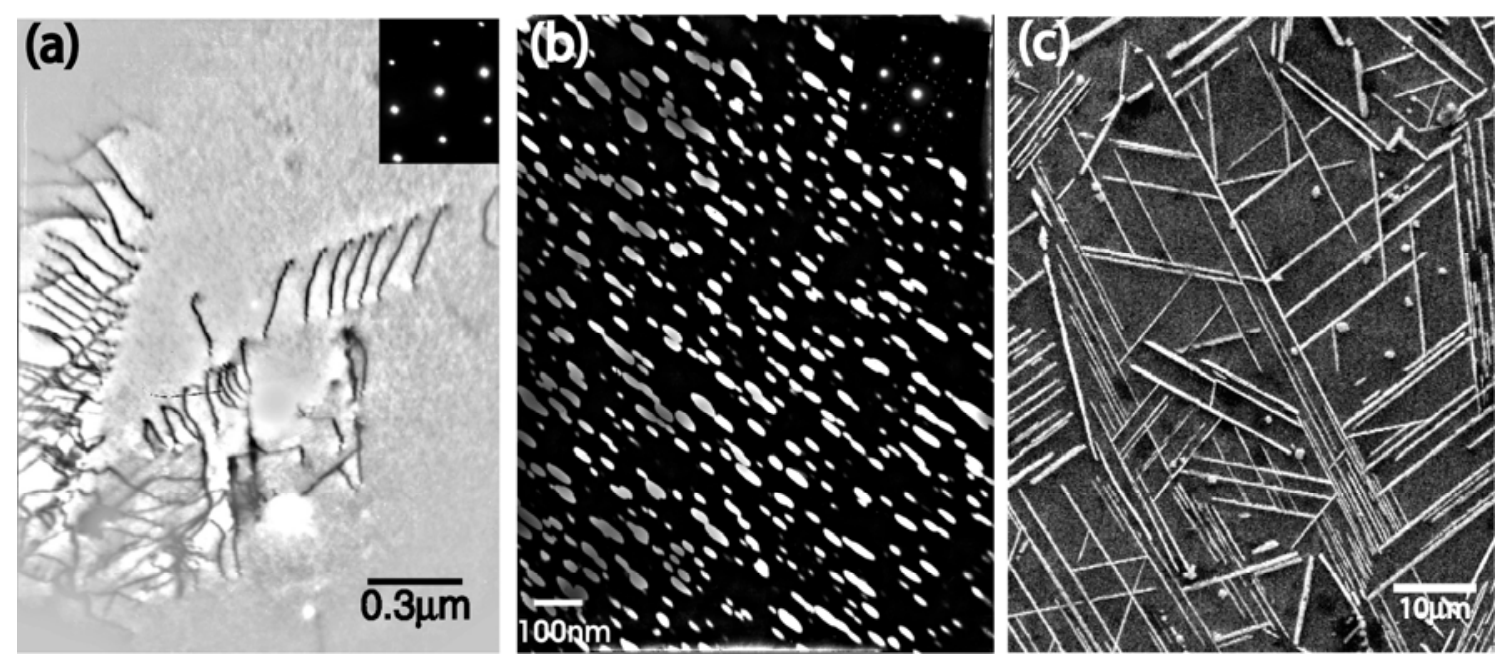

Figure 1. Typical microstructure of (a) ST, (b) STA and (c) DELTA specimens

at $900^{\circ} \mathrm{C}$ for $100 \mathrm{~h}$ to precipitate $\delta$ particles (DELTA). These heat treatments were chosen to produce microstructures with maximum volume fraction of second phase precipitates that are the major intermetallic phases forming in this alloy. The heat treated specimens were polished on 600 grade silicon carbide paper and tensile tested in air on a screw driven Instron testing machine at strain rate range of $6.5 \times 10^{-5} / \mathrm{s}$ to $6.5 \times 10^{-3} / \mathrm{s}$ and temperature range of $100^{\circ} \mathrm{C}$ to $800^{\circ} \mathrm{C}$. The specimens were soaked at the test temperature for 20 minutes before starting the test. Two small coupons of every tensile tested sample were also included along with the sample in the testing furnace to identify microstructural changes occurring due to deformation. One of the coupons (designated as coupon I) was removed just before the tensile test was started while the other one (designated as coupon II) was removed along with the fractured specimen after the furnace was cooled to room temperature. Microstructure of the coupons was used as the reference microstructure developed due to thermal exposure alone in the specimen at the beginning and the end of tensile tests. Microstructures of the specimens were examined in scanning electron microscope (SEM) and transmission electron microscope (TEM). The chemical composition of matrix was carried out by energy dispersive analysis (EDS) attached to SEM for ST and DELTA specimens.

\section{Results}

\section{$\underline{\text { Initial Microstructure }}$}

Initial microstructures of the three heat treated conditions of the alloy are shown in Fig. 1(a-c). The microstructure of ST specimens (Fig. 1a) revealed a sparse distribution of primary carbides, (not visible in the field of view) and scattered arrangements of dislocations predominantly in planar arrays, formed possibly due to thermal stresses generated during quenching. The absence of any superlattice reflection in the SAD pattern, shown in the inset, indicated that no intermetallic precipitation has occurred in the ST specimens. Homogeneous distributions of all three variants of metastable $\gamma^{\prime \prime}$ precipitates with $\mathrm{D}_{22}$ structure having $\mathrm{Ni}_{3}(\mathrm{Nb}, \mathrm{Ti}, \mathrm{Al})$ composition and ellipsoidal morphology, and spherical $\gamma^{\prime}$ particles with $\mathrm{L}_{2}$ structure with $\mathrm{Ni}_{3}(\mathrm{Al}, \mathrm{Ti})$ composition $[15,16]$ are observed in STA specimens; an illustrative dark field (DF) image of one of the variants of $\gamma^{\prime \prime}$ precipitate is shown in Fig. 1b. Average diameter of the $\gamma^{\prime \prime}$ precipitate 


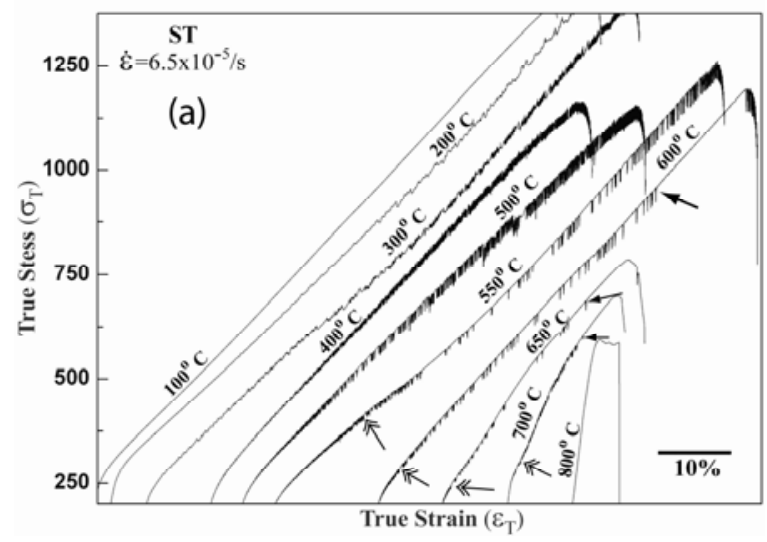

(d)
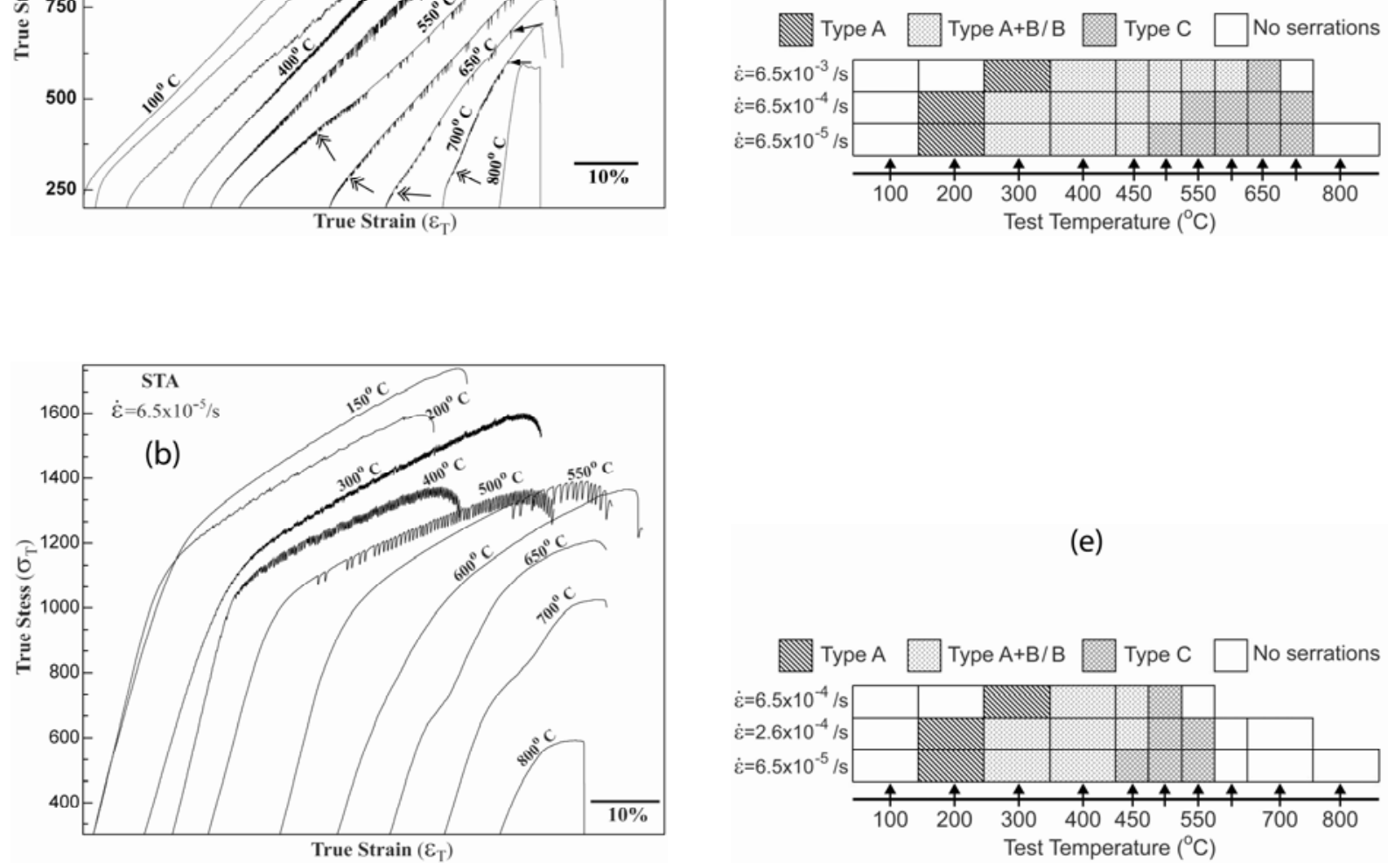

(e)
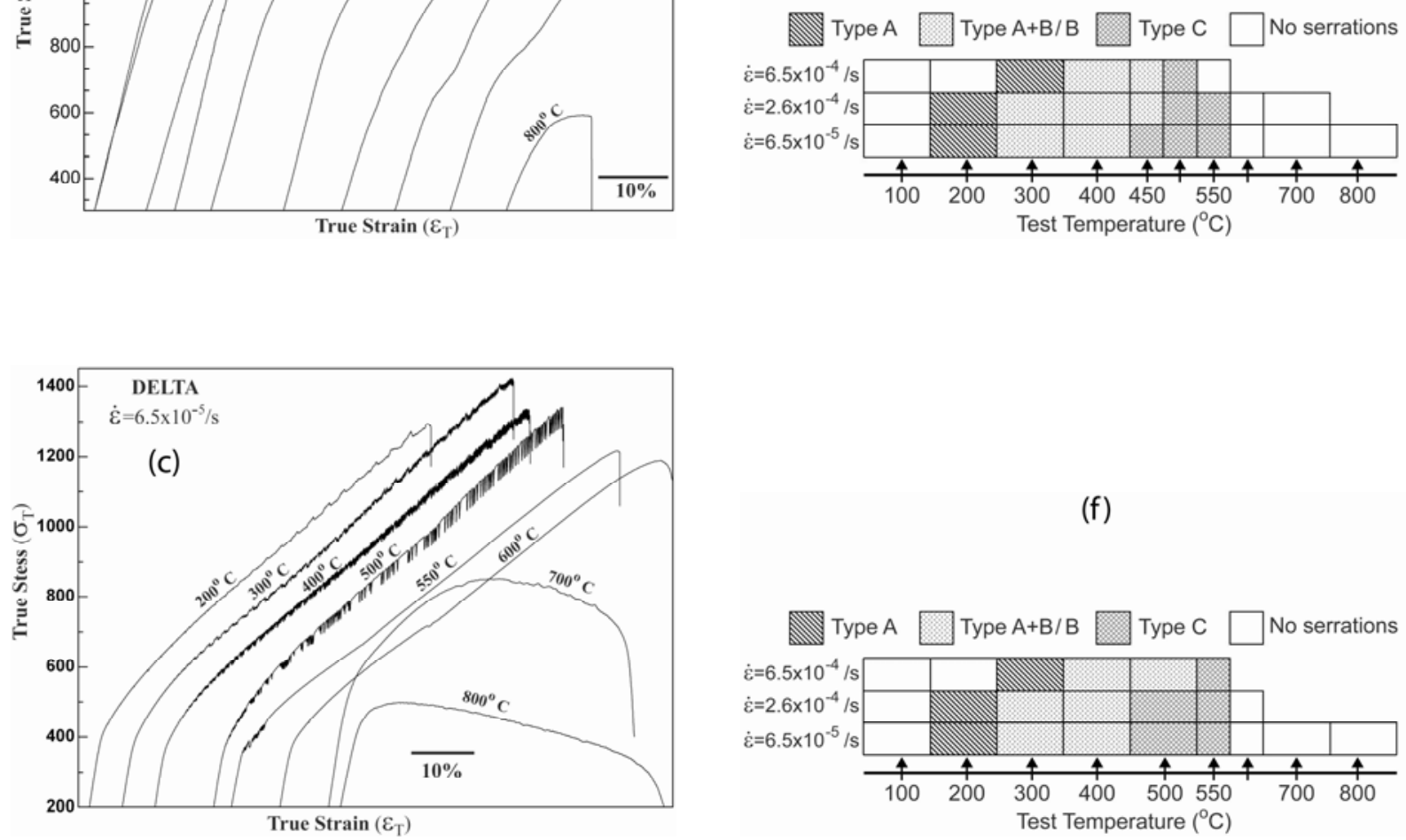

(f)

Figure 2. Stress strain plot for (a) ST, (b) STA and (c) DELTA specimens tested at different test temperatures at strain rate of $6.5 \times 10^{-5} / \mathrm{s}$. (d) to (f) represent the schematic showing the presence of serrations and their nature for different strain rates. 
measured as the length of the major axis of their 2D projections in DF images is estimated to be $28 \mathrm{~nm}$. The superlattice reflections seen in the [001] SAD pattern (inset of Fig. 1b) confirmed the presence of all variants of $\gamma^{\prime \prime}$ and $\gamma^{\prime}$ phases. The DELTA specimens (Fig. 1c) revealed a uniform and dense distribution of needle shaped orthorhombic $\delta$ precipitates.

$\underline{\text { True stress }\left(\sigma_{\mathrm{T}}\right)-\text { true strain }\left(\varepsilon_{\mathrm{T}}\right) \text { plots }}$

Figure 2a-c shows the true stress-true strain plots of ST, STA and DELTA specimens at all test temperatures for a strain rate of $6.5 \times 10^{-5} / \mathrm{s}$. Serrations were present on the flow stress curve in the temperature range of 200 to $700^{\circ} \mathrm{C}$ in the case of ST specimens (Fig. 2a) while they disappeared above $550^{\circ} \mathrm{C}$ for STA and DELTA specimens (Fig. 2b and c). Generally, five types of serrations, termed A, B, C, D and E, have been observed in the stress strain curves depending upon the test temperature and strain rate [18]. The serrations of types A, B and C, are commonly observed, while D and E type serrations are rarely seen. Amplified view of A, B, and C type serrations, observed in the present study, are shown in Figure 3. The type A serrations are characterized by an abrupt rise in stress followed by a drop to a value below the mean level of

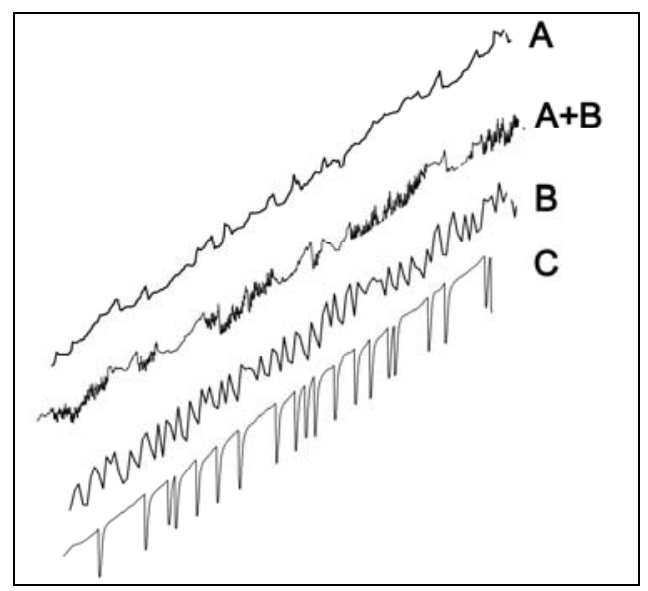

Figure 3. Amplified view of different types of serrations noticed in the present study.

the stress strain curve. They are noticed to occur in the low temperature (high strain rate) part of DSA regime. Type B serrations are oscillations about the mean level of the stress strain curve and they often develop from those of type A with increasing strain. They also occur at the onset of serrated yielding at high temperatures and low strain rates. Type A and B serrations are considered as locking serrations since the stress level goes above the general level of the flow stress curve. The type $\mathrm{C}$ serrations generally appear as yield drops that occur below the general level of the flow curve and they are considered to be unlocking the dislocations from the solute atmosphere. In the present study, for all the specimens, serrations were initiated by a type A and/or type $A+B$ serrations that changed to type $C$ serrations beyond a particular temperature. Type $\mathrm{C}$ serrations were usually accompanied with a strong audible 'tuck' sound during each load drop. For all three microstructural conditions, the transition from the type $\mathrm{A}$ and type $\mathrm{A}+\mathrm{B}$ to type $\mathrm{C}$ serrations occurred at $\sim 500^{\circ} \mathrm{C}$. Similar observations regarding the nature of serrations in this temperature range has been reported by Hayes [2]. For the ST specimens for test 

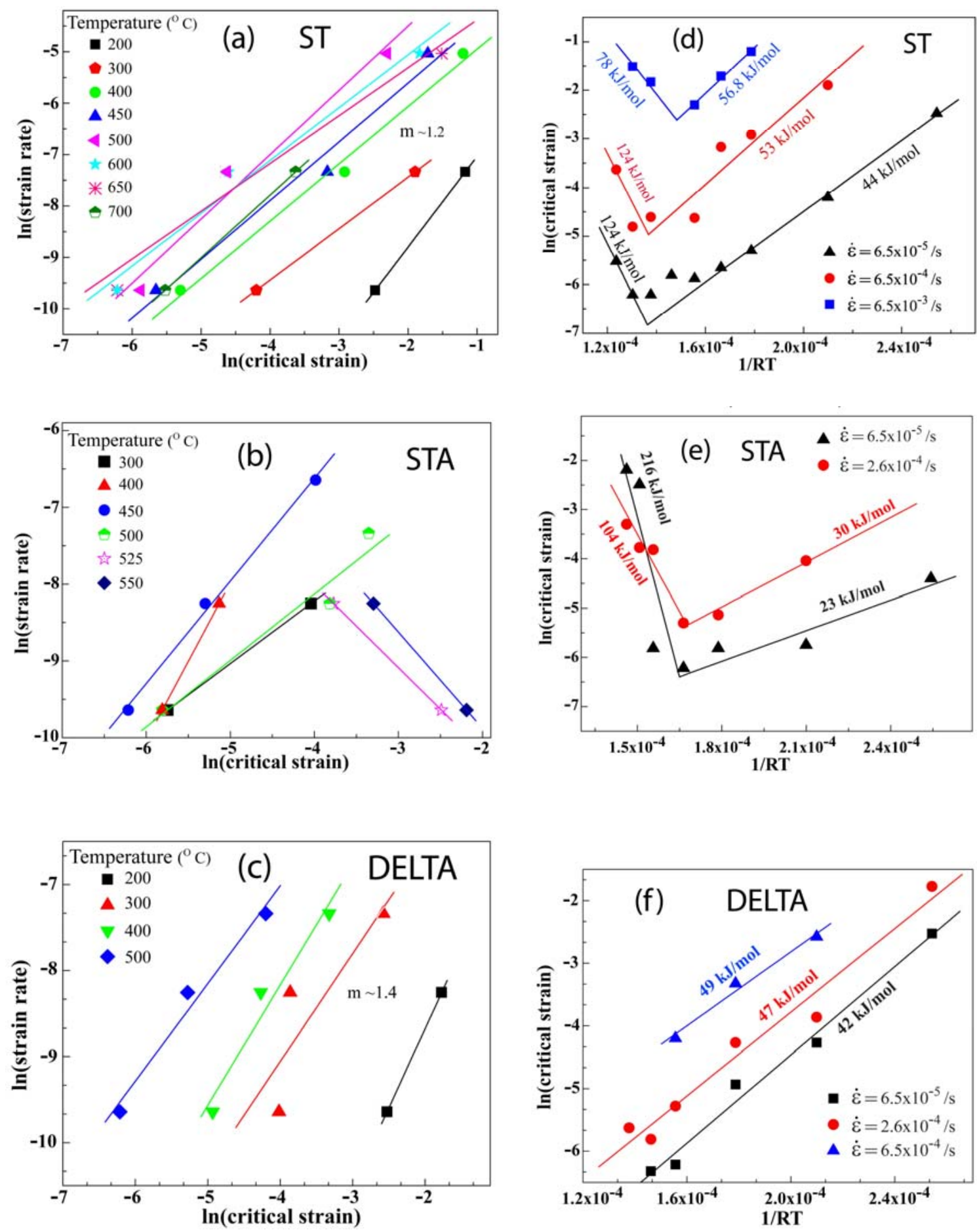

Figure 4. The $\ln \dot{\varepsilon}$ versus $\ln \varepsilon_{\mathrm{c}}$ and the $\ln \varepsilon_{\mathrm{c}}$ versus $1 / \mathrm{T}$ plots are revealed in (a), (b), (c) and (d), (e), (f) respectively. (a) and (d), (b) and (e), (c) and (f) correspond to ST, STA and DELTA specimens respectively. 
temperatures above $500^{\circ} \mathrm{C}$, the serrations were initially of complex B type, which changed to $\mathrm{C}$ type beyond a critical strain. The strain at which this change occurred is marked by double headed arrows in Figure 2a and it decreased with increase of test temperature for a constant strain rate. This type of behavior has been reported by Venkadesan et al [19] in 316 stainless steel. A broad view of the test temperature regimes for the occurrence of serrations and their nature, for different strain rates, as per the classification scheme given by Rodriguez [18], is presented in Fig. $2 \mathrm{~d}$ to e.

It could be observed from the Figure $2 \mathrm{a}$ to $\mathrm{c}$ that serrations started appearing on each flow curve at a critical strain, $\varepsilon_{\mathrm{c}}$. The magnitude of this strain was found to vary with temperature and strain rate. The plot of these dependencies is shown in Figure 4 . The $\ln \dot{\varepsilon}$ versus $\ln \varepsilon_{\mathrm{c}}$ plot always exhibited a positive slope for the range of testing parameters employed in the present study for ST and DELTA specimens while it exhibited a positive slope up to a certain temperature and negative one beyond it. The plot of the $\ln \varepsilon_{\mathrm{c}}$ versus $1 /$ T showed normal behaviour $\left(\varepsilon_{\mathrm{c}}\right.$ decreasing with increase of test temperature) for all microstructures up to test temperature of $500^{\circ} \mathrm{C}$ while it displayed an inverse behaviour ( $\varepsilon_{\mathrm{c}}$ increasing with increase of test temperature positive) at $\mathrm{T}$ above $525{ }^{\circ} \mathrm{C}$ only for ST and STA specimens. In ST specimens, above $550^{\circ} \mathrm{C}$ and $6.5 \times 10^{-5} / \mathrm{s}$ strain rate, serrations started disappearing at a $\varepsilon_{\mathrm{cd}}$ value towards the end part of flow curves (see arrow marks in Fig. 2a). The critical strain for the disappearance, $\varepsilon_{c d}$, of serrations showed a positive dependence on $\dot{\varepsilon}$ and a negative dependence on T (Fig. 5) similar to that noticed by Hayes [2].

\section{$\underline{\text { Activation Energy for Serrated Flow }}$}

The kinetic parameters associated with serrated yielding have been evaluated using various methods described in the literature [6]. The plots given in Figure 4 and 5 could be fitted with an expression of the form

$$
\varepsilon_{c}^{m+\beta}=K \dot{\varepsilon} \exp \left(\frac{\mathrm{Q}}{\mathrm{RT}}\right)
$$
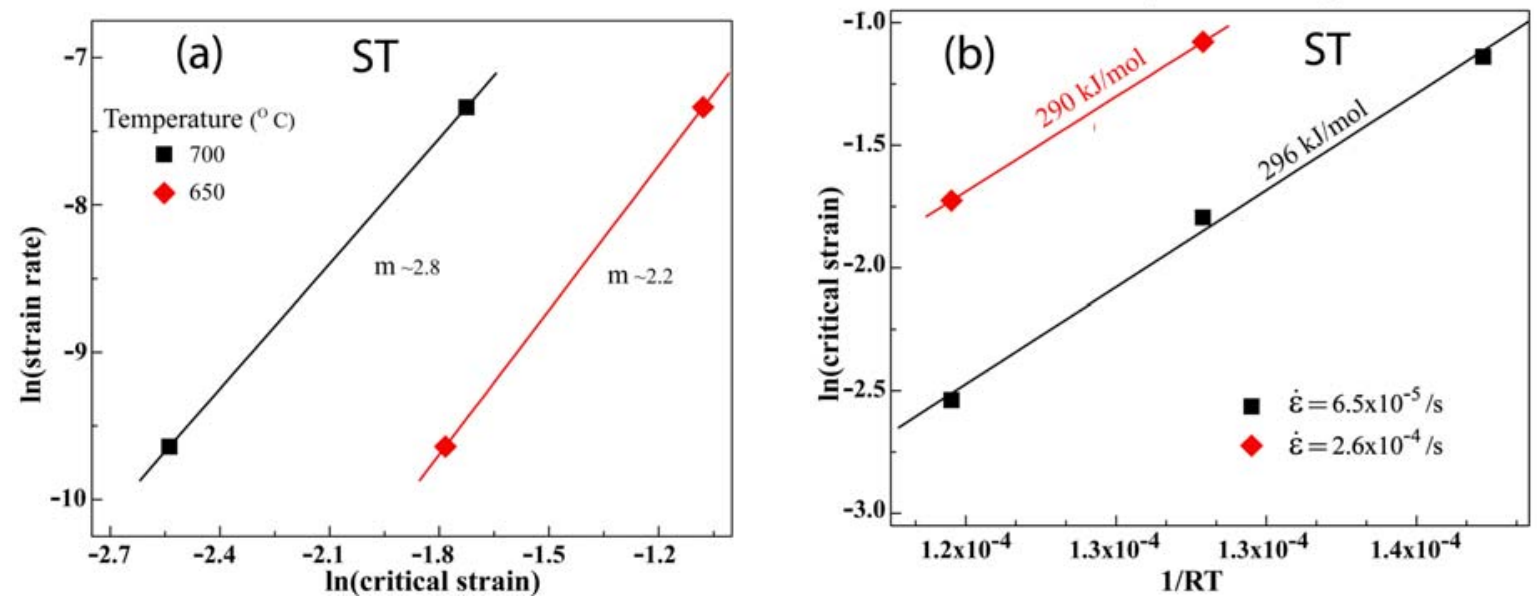

Figure 5. (a) The $\ln \dot{\varepsilon}$ versus $\ln \varepsilon_{\mathrm{c}}$ and (b) the $\ln \varepsilon_{\mathrm{c}}$ versus $1 / \mathrm{T}$ plots for disappearance of serrations in ST specimens. 
where $m$ and $\beta$, respectively, represent the variation in vacancy concentration, $C_{v}\left(\propto \varepsilon^{m}\right)$, and mobile dislocation density, $\rho_{m}\left(\propto \varepsilon^{\beta}\right)$, with plastic strain during deformation; $K$ is a constant; $Q$ is the activation energy of the diffusing species; $\mathrm{R}$ is the universal constant; and $\mathrm{T}$ is the absolute temperature. The activation energy parameters determined for different microstructures in the present study is compiled in Table I along with that reported in the literature. The $(m+\beta)$ values estimated from the plots are mentioned in the parenthesis along with $\mathrm{Q}$ values. An activation energy value of $\sim 53 \mathrm{~kJ} / \mathrm{mol}$ was obtained for Type $\mathrm{A} / \mathrm{B}$ serrations seen up to $500^{\circ} \mathrm{C}$ for all microstructures while an average activation energy value close to $210 \mathrm{~kJ} / \mathrm{mol}$ was obtained for Type $\mathrm{C}$ serrations seen above $500^{\circ} \mathrm{C}$ in ST and STA microstructures. The value of $(m+\beta)$ for the normal behavior range was found to be near 1.3 for all initial microstructures and is in conformity with that reported for interstitial diffusion in alloys [12]. The value of $(m+\beta)$ above 2 obtained for the inverse behavior regime for ST and STA specimens matches with that reported for formation of atmospheres by substitutional solutes around dislocations in the literature $[5,6,12]$.

\section{Deformation microstructure}

Deformation microstructure of specimens prepared from gauge portions near the fractured edge of samples corresponding to all the three microstructures were comprised mainly of high densities of dislocations confined within slip bands for test temperatures below $500^{\circ} \mathrm{C}$ (Figure

Table 1. The activation energy for serrated flow taken from the literature, earlier publications of present authors and determined from data presented in this paper

\begin{tabular}{|c|c|c|c|c|}
\hline \multirow{2}{*}{$\begin{array}{c}\text { Initial } \\
\text { Microstructure }\end{array}$} & \multirow{2}{*}{$\begin{array}{l}\text { Analysis } \\
\text { method }\end{array}$} & \multicolumn{2}{|c|}{$\begin{array}{c}\text { Activation Energy }(\mathrm{kJ} / \mathrm{mol}) \text { for test } \\
\text { temperatures }\end{array}$} & \multirow{2}{*}{ Reference } \\
\hline & & $\begin{array}{c}\mathrm{T}<\sim 525^{\circ} \mathrm{C} / \\
\text { serrations type } \mathrm{A} / \mathrm{B}\end{array}$ & $\begin{array}{l}\mathrm{T}>\sim 525^{\circ} \mathrm{C} / \\
\text { type } \mathrm{C}\end{array}$ & \\
\hline \multirow{4}{*}{ ST } & $\varepsilon_{\mathrm{ca}}$ method & $44(1.3)$ & $109(1.3)$ & \\
\hline & $\Delta \sigma$ method & 50 & - & \\
\hline & $\varepsilon_{\mathrm{cd}}$ method & - & $293(2.6)$ & \\
\hline & $\begin{array}{c}\text { Average of five } \\
\text { methods }\end{array}$ & 117 & 225 & {$[5,6]$} \\
\hline \multirow{5}{*}{ STA } & $\varepsilon_{\mathrm{ca}}$ method & $27(1.0)$ & $160(1.0)$ & \\
\hline & $\Delta \sigma$ method & 60 & - & \\
\hline & $\varepsilon_{\mathrm{ca}}$ method & 72 & - & {$[4]$} \\
\hline & $\varepsilon_{\mathrm{cd}}$ method & - & 261 & {$[2]$} \\
\hline & $\Delta \sigma$ method & 43 & - & {$[2]$} \\
\hline \multirow{2}{*}{ DELTA } & $\varepsilon_{\mathrm{ca}}$ method & $46(1.4)$ & - & \\
\hline & $\Delta \sigma$ method & 42 & - & \\
\hline Average & & 53 & 210 & \\
\hline
\end{tabular}



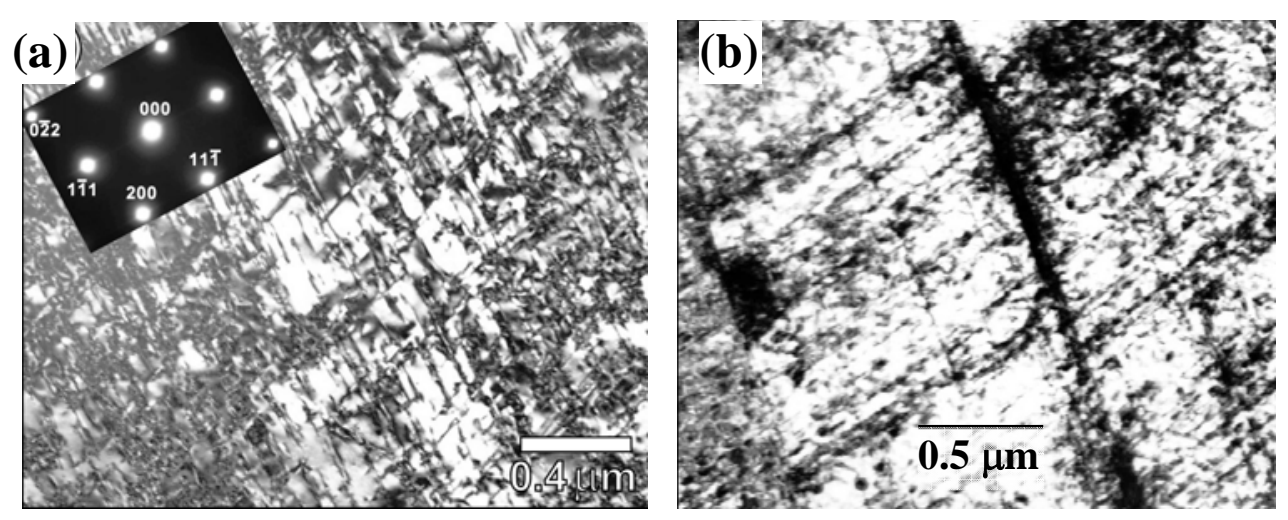

Figure 6. Deformation microstructure of (a) ST, (b) STA and (c) DELTA specimens tested at $500^{\circ} \mathrm{C}$.

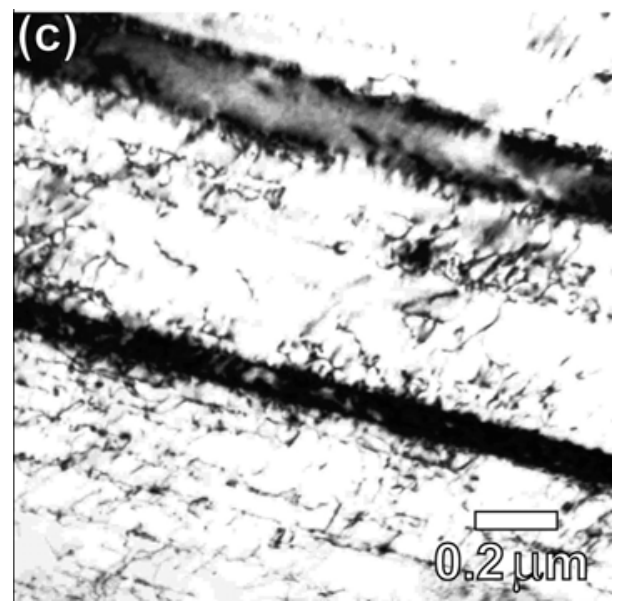

6). STA samples, in addition, revealed frequent shearing (at low test temperatures) as well as twinning (at high temperatures) of the $\gamma^{\prime \prime}$ precipitates (Figure 7). The details of the observation of increased twinning activity with deformation temperature will be reported separately. In the case of ST samples, tested at $\mathrm{T} \geq 550^{\circ} \mathrm{C}$ and strain rate $6.5 \times 10^{-5} / \mathrm{s}$, the microstructure revealed splitting of dislocations into partials (Figure 8). The selected area diffraction pattern taken from these regions revealed superlattice reflections corresponding to $\gamma^{\prime}$ and $\gamma^{\prime \prime}$ precipitates. However, the precipitate particles could not be imaged in the DF indicating that probably their size was below the resolution limit of the microscope. The mechanism of splitting of perfect matrix dislocations into partials in Alloy 718 has been explained in an earlier paper [20]. The nonobservation of $\gamma^{\prime \prime}$ precipitation in coupons taken out just before beginning as well as the end of test confirmed that these precipitates have formed only as a result of deformation (Figure 9). However, microstructural examination of specimens tested at $\mathrm{T} \geq 650^{\circ} \mathrm{C}$ indicated that $\gamma^{\prime \prime}$ has precipitated as a result of thermal exposure itself. In the case of DELTA microstructure, only $\gamma^{\prime}$ at $\mathrm{T}=600^{\circ} \mathrm{C}$ and $\gamma^{\prime}$ and $\gamma^{\prime \prime}$ at $\mathrm{T}=700^{\circ} \mathrm{C}$ have precipitated in the deformed specimens. These observations are rationalized on the basis of the relative concentration of $\mathrm{Al}$, $\mathrm{Ti}$ and $\mathrm{Nb}$ in the matrix of $\delta$ precipitated Alloy 718 microstructure [21].

\section{Discussion}

In the present study, the true stress-true strain curves showed serrated phenomenon at test temperatures up to $700^{\circ} \mathrm{C}$ in ST specimens (Fig. 2a), whereas in the case of STA and DELTA samples, serrations were seen only up to a temperature of $550^{\circ} \mathrm{C}$ (Fig. $2 \mathrm{~b}$ and c). Such 

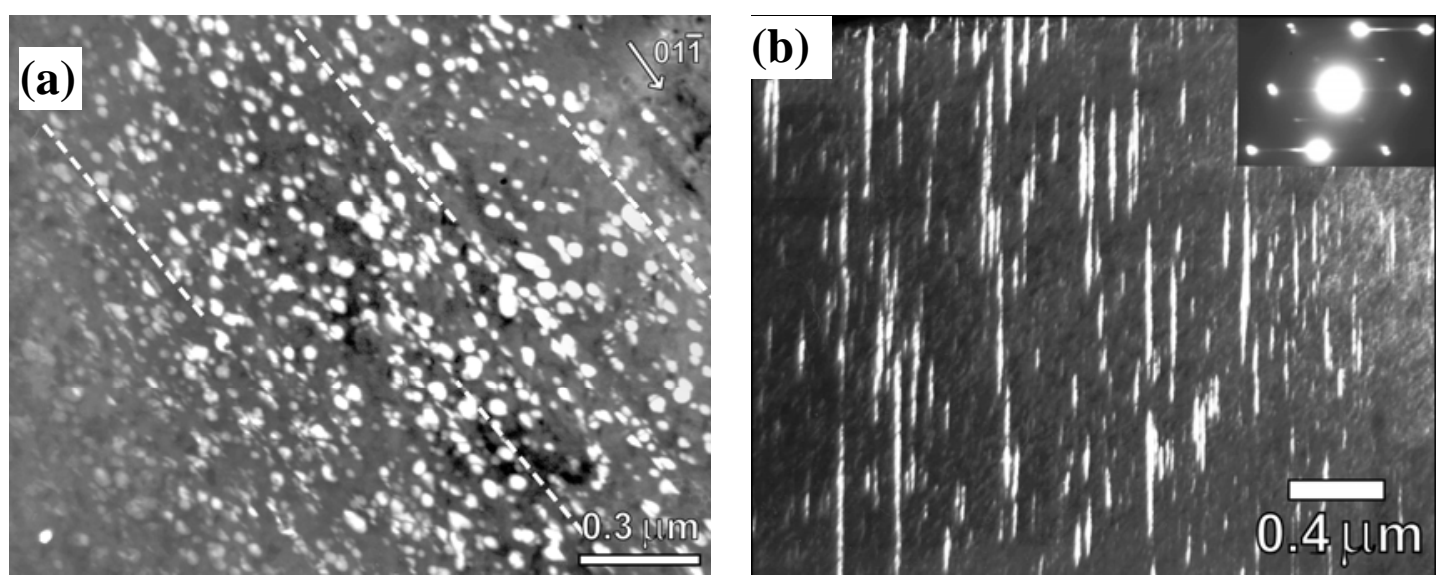

Figure 7. Dark field image showing (a) shearing of $\gamma^{\prime \prime}$ precipitates at $\mathrm{T}=500^{\circ} \mathrm{C}$ and (b) twinning within $\gamma^{\prime \prime}$ precipitates at $\mathrm{T}=700^{\circ} \mathrm{C}$ in STA specimen tested at a strain rate of $6.5 \times 10^{-5} / \mathrm{s}$.

phenomenon has been interpreted in the literature due to the formation of an atmosphere of solute atoms around dislocations and depending on the measured $\mathrm{Q}$ values, various elements are assumed to be responsible [2-9]. The activation energy for the serrated flow determined using $\varepsilon_{\text {ca }}$ and $\Delta \sigma$, measured during the present investigations $[12,22]$ is tabulated in Table 1 . The activation energy values estimated by other researchers in this alloy are also given in the table. The test regimes have been broadly classified into two - one below $525^{\circ} \mathrm{C}$ and the other above $525^{\circ} \mathrm{C}$ - on the basis of estimated activation energy and the mechanism for the serrated flow put forward in the literature [6,7]. The transition in most cases does not occur at a unique temperature but lies within a band of $\pm 25^{\circ} \mathrm{C}$. As mentioned in the result section, the average value of the activation energy determined by various researchers for temperatures lower than $525^{\circ} \mathrm{C}$ is $\sim 53 \mathrm{~kJ} /$ mole (Table 1 ). Since this value is very close to that for the diffusion of interstitial carbon in the nickel matrix [23], the mechanism for serrated phenomena at lower temperatures in the present study can also be attributed to interstitial carbon atoms [2 - 7]. The deviation from the average activation energy value has been attributed to the waiting time of mobile dislocations under the influence of pinning atmospheres in different microstructures, as well to draining of carbon atmosphere from dislocations to sinks by pipe diffusion [4]. The inverse behavior is noticed at high temperatures in the present study in the case of only ST and STA specimens and the average activation energy is around $210 \mathrm{~kJ} / \mathrm{mole}$ (Table 1 ). This value is very close to the activation energy for diffusion of solutes like chromium, niobium, and molybdenum in nickel [18]. In fact, Hale et al. [6] have explained the appearance of serrations at high temperature to the diffusion of carbide-forming chromium solute to dislocations. Hayes [2] attributed the high activation energy to the diffusion of niobium solute to these dislocations and forming $\mathrm{NbC}$ heterogeneously thereby depleting the carbon atmospheres, though no microstructural confirmation has been reported so far for this mechanism. In a recent study, Weaver and Hale [5] attributed the complete disappearance of serrations in a stress strain curve at all temperatures to a possible depletion of interstitial and substitutional solutes in the matrix that are tied up as precipitates. 


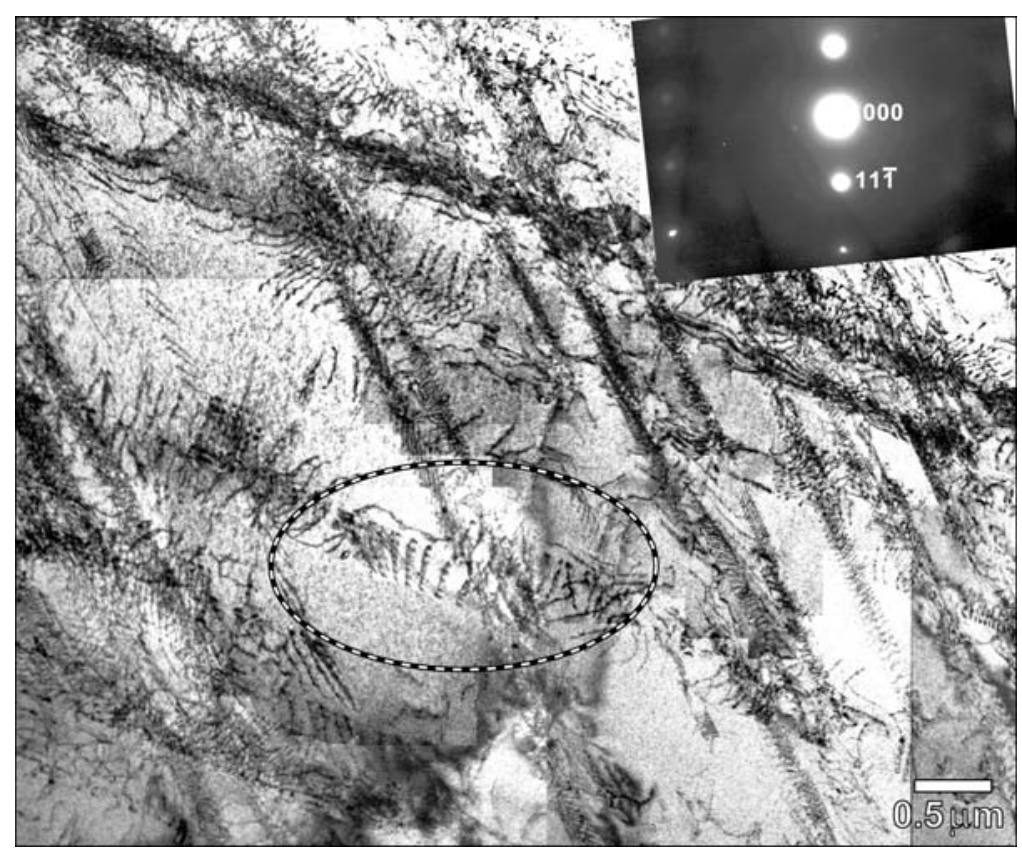

Figure 8. Splitting of unit dislocations of the matrix into partials in $\mathrm{ST}$ specimens tested at $700^{\circ} \mathrm{C}$.

The results of the present study clearly indicated that at test temperatures above $525^{\circ} \mathrm{C}$, precipitation of $\gamma^{\prime}$ and $\gamma^{\prime \prime}$ phases occur during deformation in ST specimens. It is well known that these precipitates contain about 20 to 25 at $\%$ of $\mathrm{Nb}$ in them and hence their precipitation is expected to bring down the concentration of niobium in the matrix depending upon the volume fraction precipitated. The depletion should be high in those alloys where maximum volume fraction of $\gamma^{\prime \prime}$ and $\delta$ precipitates have formed. As mentioned in the experimental section, STA and DELTA specimens correspond to that category. The composition of the austenite matrix in different microstructural conditions is given in Table 2. The matrix compositions of ST and DELTA specimens were determined using EDS attached to the SEM. For the STA specimen, it is difficult to estimate the matrix composition using EDS, even attached to a TEM, without interference from the adjacent precipitates because of small inter-particle spacing due to high volume fraction of $\gamma^{\prime \prime}$ particles $(\sim 12 \%)$. Hence the composition of the matrix of solution treated and aged specimens of Alloy 718, determined by Miller [24] using 3-D atom probe, has been used for analysis since the heat treatments employed by them is similar to the present one. It is clear from Table 2 that the precipitation of $\gamma^{\prime \prime}$ or $\delta$ phase in the alloy results in drastic reduction of niobium concentration in the matrix. Hence it is likely that the tying up of niobium in the precipitates $\left(\gamma^{\prime \prime}\right.$ or $\delta$ ) resulting in its reduced concentration in the matrix, was responsible for the absence of serrated yielding in STA and DELTA specimens of Alloy 718 at test temperatures above $550^{\circ} \mathrm{C}$. The occurrence of serrated flow at high temperatures (up to $700^{\circ} \mathrm{C}$ ) in ST samples could be related to the availability of excess niobium in the matrix, compared to that obtained in the matrix of the aged alloy. The average value for activation energy estimated for serrated flow at high temperatures in ST samples matched well with the activation energy for diffusion of niobium in nickel reported by Patil and Kale [25]. Since the concentration of chromium and molybdenum was unaffected by microstructural conditions of the alloy (Table 2), 

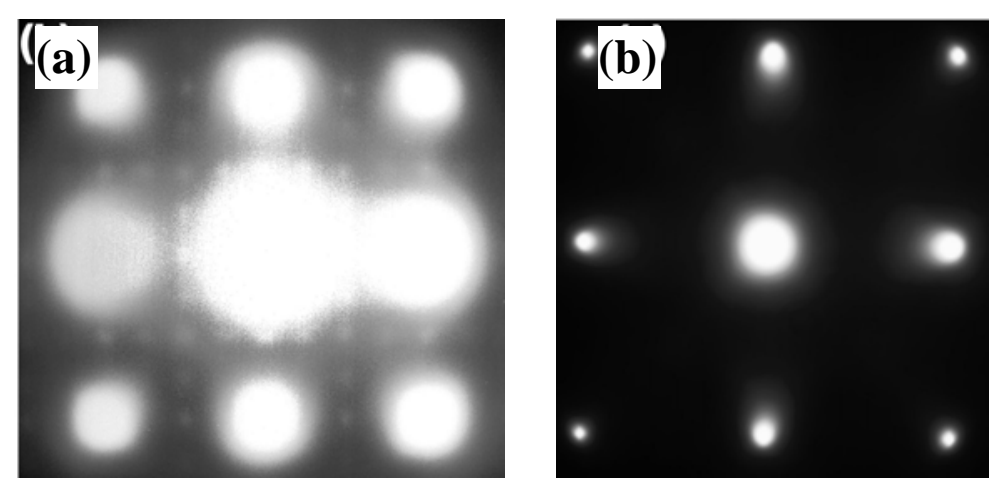

Figure 9. $<001>$ zone axis SAD pattern from (a) the fractured specimen and (b) the corresponding coupon having seen identical thermal history at $550^{\circ} \mathrm{C}$. Note the presence of superlattic reflections corresponding to $\gamma^{\prime \prime}$ precipitates in only (a) indicating that precipitation has occurred as a result of deformation.

the possibility of these elements being responsible for serrated yielding in ST samples at $\mathrm{T}>$ $525^{\circ} \mathrm{C}$ could be ruled out [6,7]. From these facts, one could reasonably conclude that the niobium solute was responsible for the occurrence or non- occurrence of serrated flow at high temperatures in Alloy 718 depending on the initial microstructural condition.

Table 2. Composition of austenite matrix in different microstructural conditions

\begin{tabular}{cccccccc}
\hline \multirow{2}{*}{ Phase } & \multicolumn{6}{c}{ Concentration of elements (in wt \%) } \\
\cline { 2 - 8 } & $\mathrm{Fe}$ & $\mathrm{Cr}$ & $\mathrm{Nb}$ & $\mathrm{Ti}$ & $\mathrm{Al}$ & $\mathrm{Mo}$ & $\mathrm{Ni}$ \\
\hline ST* $^{*}$ & 20.67 & 17.58 & 5.19 & 0.97 & 0.57 & 0.29 & $\mathrm{Bal}$ \\
STA* & 24.81 & 21.23 & 2.57 & 0.39 & 0.26 & 3.55 & Bal. \\
ST & 18.02 & 18.20 & 5.99 & 1.09 & 0.94 & 3.89 & Bal. \\
DELTA & 19.48 & 19.95 & 3.85 & 0.84 & 1.1 & 0.42 & Bal. \\
\hline * Reference [24] & & & & & &
\end{tabular}

It is clear from the preceding paragraph that at test temperatures $>525^{\circ} \mathrm{C}$, diffusion of $\mathrm{Nb}$ to dislocations and formation of $\mathrm{Nb}$ atmospheres around them appeared to be responsible for serrated yielding phenomena in ST samples. It is also clear from the results that precipitation of $\gamma$ " occurred during deformation at $\mathrm{T}>500^{\circ} \mathrm{C}$. Hence, one could surmise that $\mathrm{Nb}$ in the matrix has to partition between precipitates and dislocations. In such a situation, kinetics of precipitation determines the extent of $\mathrm{Nb}$ available for pinning dislocations at any instant and it decreases with increasing test temperature. Moreover, if SY occurs until the end of fracture of the specimen, sufficient solute should be available in the matrix at all stages to pin dislocations, since their density is increasing with strain. Thus, a critical concentration of $\mathrm{Nb}$ solute appears necessary at all times for serrated yielding to occur. If due to partitioning of $\mathrm{Nb}$ between increasing dislocation density and $\gamma^{\prime \prime}$ precipitation, the $\mathrm{Nb}$ concentration falls below this critical value at a 
strain $\varepsilon_{\mathrm{cd}}$ before fracture at test temperature, and the serrations will disappear from that point in the stress strain response. From the present results, it appears that at $600^{\circ} \mathrm{C}$, sufficient $\mathrm{Nb}$ is not available to pin dislocations until fracture. At $700^{\circ} \mathrm{C}$, since precipitation of $\gamma^{\prime \prime}$ is seen as result of thermal exposure itself, it is possible that due to quick depletion of $\mathrm{Nb}$ from the matrix in fast $\gamma^{\prime \prime}$ precipitation kinetics, sufficient $\mathrm{Nb}$ is not available at any stage to completely pin the dislocations, resulting in the disappearance of SY. This model is consistent with the present experimental observations. The possibility of $\mathrm{NbC}$ formation responsible for disappearance of serrations as suggested by Hayes [2] could be ruled out here, as no evidence for this phenomenon was observed on detailed microstructural examination of fractured specimens.

\section{Conclusions}

On the basis of the present study in Alloy 718, one could arrive at the following conclusions:

1. Serrations in ST appear up to a test temperature of $700^{\circ} \mathrm{C}$, while in STA and DELTA specimens, serrations are seen only up to $550^{\circ} \mathrm{C}$.

2. A transition from a normal to inverse serrated behavior occurs above a test temperature of $525^{\circ} \mathrm{C}$ for ST and STA specimens.

3. The formation of interstitial carbon atmospheres around mobile dislocations is found to be responsible for the serrated yielding in the normal behavior regime from the activation energy considerations while the inverse behavior is attributed to interaction of substitutional niobium solutes with dislocations.

4. The reduction of niobium atoms in the matrix as a result of precipitation during initial heat treatment is responsible for the absence of serrations in the aged alloy (STA and DELTA) above $550^{\circ} \mathrm{C}$.

5. The observation of delayed disappearance of serrations at elevated temperature tests in ST specimens is attributed to deformation induced precipitation of $\gamma^{\prime \prime}$ precipitates.

\section{Acknowledgements}

The authors would like to thank Dr. J. K. Chakravartty, Head, Mechanical Metallurgy Section, Bhabha Atomic Research Centre for useful discussions and Dr. A. K. Suri, Director, Materials Group for keen interest and support for this work.

\section{References}

1. R.W. Hayes and W.C. Hayes, "On the mechanism of delayed discontinuous plastic flow in age hardened Ni alloy”, Acta Metallurgica, 30 (1982), 1295-1301.

2. R.W. Hayes, "On a proposed theory for disappearance of serrated flow in FCC Ni alloys", 31 (1983), Acta Metallurgica, 365-371. 
3. Vani Shankar, M. Valsan, K.B.S. Rao and S. L. Mannan, "Effects of temperature and strain rate on tensile properties and activation energy for dynamic strain ageing in alloy 625”, Metallurgical \& Materials Transactions, 35A (2004), 3129-3139.

4. W. Chen and M.C. Chaturvedi, "On the mechanism of serrated deformation in aged Inconel 718”, Materials Science \& Engineering, 29A (1997), 163-168.

5. M.L. Weaver and C.S. Hale, "Effect of precipitation in serrated yielding in Inconel 718", Superalloys 718, 625, 706 \& Various Derivatives, ed. E. A. Loria (TMS, The Minerals, Metals \& Materials Society, 2001), 421-432.

6. C. S. Hale, W.S. Rollings and M.L. Weaver, "Activation energy calculations for discontinuous yielding in Inconel 718SPF", Materials Science \& Engineering, 300A (2001), 153-164.

7. S. A. Nalawade, R. Kishore and M. Sundararaman, "Analysis of dynamic strain ageing in Alloy 718”, ISRS (International Symposium for Research Scholars on Metallurgy, Materials Science \& Engineering, Chennai, India, December 2006).

8. S.A. Nalawade, M. Sundararaman, R. Kishore and J.G. Shah, "The influence of ageing on the serrated yielding phenomena in a nickel base superalloy", Scripta Materialia, 59 (2008) 991-994.

9. R.A. Mulford and U.F. Kocks, "New observations on the mechanisms of dynamic strain ageing and of jerky flow", Acta Metallurgica, 27 (1979), 1125-1134.

10. K. Gopinath, A. K. Gogia, S. V. Kamat and U. Ramamurthy, "Dynamic strain ageing in nickel base superalloy 720Li”, Acta Materialia, 57 (2009) 1253-1263.

11. A.H. Cottrell, "A note on the Portevin-Le Chatelier effect", Philosophical Magazine, 44 (1953), 829- 832.

12. P.G. McCormik, "A model for the Portevin-Le Chatelier effect in substitutional alloys", Acta Metallurgica, 20 (1972), 351-354.

13. I.S. Kim and M.C. Chaturvedi, "Serrated flow in Inconel 625", Transactions of Japan Institute of Metals, 28 (1987) 205-212.

14. J. M. Oblak, D.S. Duvall and D.F. Paulonis, "Coherency strengthening in nickel base superalloys hardened by $\mathrm{D0}_{22} \gamma$ " precipitates", Metallurgical Transactions, 5, (1974), 143-153

15. M. Sundararaman, P. Mukhopadhyay and S. Banerjee, "Some aspects of the precipitation of metastable intermetallic phases in Inconel 718", Metallurgical Transactions, 23A (1992), 2015-2028.

16. M.C. Chaturvedi and Ya-fang Han, "Strengthening mechanisms in Inconel 718 superalloy", Metal Science, 17 (1983), 145-149.

17. M. Sundararaman, P. Mukhopadhyay and S. Banerjee, "Precipitation of the $\mathrm{Ni}_{3} \mathrm{Nb}$ phase in two nickel base superalloys", Metallurgical Transactions, 19A (1988), 453-465.

18. P. Rodriguez, "Serrated plastic flow”, Bulletin of Materials Science, 6 (4) (1984), 653663. 
19. S. Venkadesan, C. Phaniraj, P. V. Sivaprasad and P. Rodriguez, "Activation energy for serrated flow in a $15 \mathrm{Cr}-15 \mathrm{Ni}$ Ti modified austenitic stainless steel", Acta Metallurgica et Materialia., 40 (1992), 569-580.

20. M. Sundararaman, P. Mukhopadhyay and S. Banerjee, "Deformation behavior of $\gamma$ " strengthened Inconel 718", Acta Metallurgica, 36 (1988), 847-864.

21. S. A. Nalawade, M. Sundararaman, J.B. Singh, A. Verma and R. Kishore, "Precipitation of $\gamma^{\prime}$ phase in $\delta$-precipitated Alloy 718 during deformation at elevated temperatures", Materials Science \& Engineering, 527A (2010), 2906-2909.

22. S.A. Nalawade, "Mechanical behavior of Inconel 718 at elevated temperatures" (Ph.D thesis, University of Mumbai, 2009)

23. Y. Nakada and A.S. Keh, "Serrated flow in Ni-C alloys" Acta Metallurgica, 18 (1970), 437-443.

24. M.K. Miller, S.S. Babu and M.G. Burke, "Comparison of the phase compositions in Alloy 718 measured by atom probe tomography and predicted by thermodynamic calculations", Materials Science \& Engineering, 327A (2002), 84-88.

25. R.V. Patil, G.B. Kale, "Chemical diffusion of niobium in nickel", Journal of Nuclear Materials, 230 (1996), 57-60. 